\title{
La integración latinoamericana en la historiografía cubana: El caso de la Confederación Antillana
}

\section{RAMON DE ARMAS}

Muy poca utilidad tendría este artículo, si nos limitáramos en él a mencionar las causas más probables por las cuales la historiografía cubana pre y postevolucionaria no abordó ni atendió -salvo muy escasas excepciones- las aspiraciones de integración latinoamericana presentes en los ideólogos, dirigentes y protagonistas dé casi medio siglo de luchas por la independencia cubana, y muy particularmente-puesto que es el tema de este trabajo- las ideas de unión y confederación antillanas que tuvieron vigencia y presencia entre ellos durante los años 60 , 70 y 80 del XIX cubano.

Precisamente por esa ausencia historiográfica, nos consideramos ineludiblemente obligados a ofrecer aquí, al menos, una muestra sintética y no exhaustiva de la presencia de estas últimas en muy importantes grupos, 'organizaciones y dirigentes de la mayor de las Antillas, antes de analizar, sobre esa base, las causas que pueden haber determinado, hasta hoy, tan sensible ausencia.

Los ejemplos reseñados no agotan, desde luego, los que un abordaje más detenido debe poner de manifiesto, pero pueden dar una idea sumaria del peso, la significación y la fuerza que las mismas tuvieron entre los hombres que bregaron durante décadas por la independencia y la soberanía de la patria cubana, y de la común patria antillana. Lo hacemos, también, porque consideramos que en el propio conocimiento de estos aspectos aún casi ignorados de nuestra historia nacional está -precisamente- la clave para explicar su falta de tratamiento por parte de nuestra historiografía nacional. Intentaremos sintetizar los contenidos fundamentales de las diversas manifestaciones cubanas ya detectadas de estas ideas confederacionistas, en la medida en que el espacio de que disponemos nos lo permita.

1865: Se funda en Nueva York, por emigrados cubanos y puertorriqueños, la Sociedad Republicana de Cuba y Puerto Rico, con ramificaciones en Filadelfia y Nueva Orleáns. Aunque el acta de fundación proclama solamente el objetivo de "poner en ejercicio los medios que estén a nuestro alcance para separar a Cuba y Puerto Rico de la dominación española y adquirir una patria libre e independiente" (1), fuentes historiográficas puertorriqueñas han demostrado (2) que la Socie-

(1) Lidio Cruz Monclova: Historia de Puerto Rico (siglo XLX), T. 1, Río Piedra's, Editorial Universitaria, 1970, p. 435.

(2) Ver: Carlos M. Rama: La idea de la federación antillana en los independentistas puertorriqueños del siglo XIX, Río Piedras, Ediciones Librería Internacional, 1971. 
dad tuvo vinculación -si no programática, al menos práctica- con el objetivo de crear una Confederación de las Antillas. Sin embargo -por motivos ajenos a nuestro tema- ni su presidente (el cubano Juan Manuel Macías) ni los otros miembros de su junta directiva (3) estuvieron vinculados al estallido en Cuba de la Revolución de 1868, ni pudieron desempeñar durante la guerra un papel rector en la emigración revolucionaria cubana en Estados Unidos.

1868: La historiografía colonialista española (4) refiere el viaje que de Saint Thomas a Santo Domingo efectuó en enero de ese año Ramón Emeterio Betances, el padre de la Patria Puertorriqueña, con el fin de conferenciar, entre otros, con el mencionado presidente de la Sociedad Republicana de Cuba y Puerto Rico, y con el dominicano Cabral (entonces en lucha contra Buenaventura Báez en la República Dominicana). Afirman los historiadores españoles de la época que "el gran plan de antiguo concebido por los laborantes (o sea, por los independentistas) era proclamar una gran república federal antillana, compuesta de Cuba, Haití, Santo Domingo y Puerto Rico" (5).

1869: Según la información española, "en febrero de 1869 fue apresada una goleta haitiana en la que viajaba el general negro Boom, natural de Santo Domingo y uno de los mayores enemigos del elemento europeo en América". Siguiendo dichas fuentes, Boom conspiraba con los independentistas de Cuba y Puerto Rico "para constituir una federación republicana de todas las Antillas". Después de su captura, el Moniteur Officiel de Port-au-Prince del 6 de febrero insertó varios párrafos de las cartas que le habían sido ocupadas al prisionero, en las que se hacía referencia a "resultados importantes que se preparan en la parte dominicana y en las islas de Puerto Rico y Cuba cuyos dos Estados quieren con Santo Domingo y Haití formar una Confederación" (6).

1873: Una de las pocas figuras del independentismo cubano del siglo XTX en relación con la cual nuestra historiografía prerrevolucionaria ha hecho mención de muy definidas ideas confederacionistas es Francisco Vicente Aguilera, quien fue en 1868, junto con Carlos Manuel Céspedes, uno de los dirigentes organizadores de la Revolución que dio inicio a la Guerra de los Diez Años. Su principal biógrafo (7) afirma que Aguilera pensaba que la independencia de Cuba necesariamente habría de llevar a la de Puerto Rico, y estimaba que "unidas estas dos islas por un pacto federal que les asegurara mutuo apoyo" podrían asegurar su rápido engrandecimiento. Santo Domingo y Haití, atraídas por la prosperidad de sus dos vecinas, no tardarían en ingresar al pacto federal, y "unidas las tres islas, formarian un núcleo poderoso que gradualmente iría creciendo con la atracción del archipiélago de las Antillas", hasta constituir la Confederación Antillana que Aguilera contemplaba

(3) Entre ellos se hallaban figuras tan prominentes como Pedro Santacilia, Cirilo Villaverde, Juan Clemente Zenea y Ramón Roa.

(4) José Pérez Moris y Luis Cueto: Historia de la Insurrección de Lares, Barcelona, 1872, p. 52.

(5) Ibid. Por su parte, Betances -firme propulsor de la Confederación de las Antillas- estuvo vinculado desde muy temprano en la década del 60 a la propaganda y el activismo revolucionario a favor de la lucha independentista cubana. En los años 90 , llegó a ser representante en París - a solicitud de Martí- del Partido Revolucionario Cubano fundado por éste.

(6) Ibid., p. 65-6 (n.3).

(7) Eladio Aguilera Rojas: Francisco Vicente Aguilera y la Revolución de Cuba de 1868, La Habana, La Moderna Poesia, 1909, t. I, p. 36 y ss. 
para los tiempos por venir. En carta de 16 de mayo de 1873 al diputado por Guadalupe Germán Cassé, Aguilera deja ver, efectivamente, su concepción de un proceso escalonado en el logro de "la proyectada Confederación", que incluiría también a las Antillas Menores, y en el que la independencia de Cuba -según postulasería "la piedra angular del edificio antillano" (8). En el mismo año 1873, decía al propio diputado por Guadalupe que la Gran Federación Antillana era "no sólo la aspiración más cara de su alma, sino la de todos los bombres pensadores de su país", según refiere el único otro historiador cubano que abordó la filiación confederacionista del importante luchador (9). Si bien no es posible determinar -en el estado actual de las investigaciones sobre el tema- el verdadero alcance de una afirmación tan generalizadora como esta; sí existen ya pruebas documentales localizadas (como veremos) de que, al menos entre la emigración revolucionaria cubana radicada en Estados Unidos -siempre estrechamente vinculada al pensamiento político prevalecente en el país- planteamientos programáticos contentivos de ideas confederacionistas recibieron muy fuerte apoyo.

1874: El periódico independiente El Republicano, de Cayo Hueso (Florida, Estados Unidos) publica en el mes de octubre una carta de Ramón Emeterio Betances al presidente de la agrupación de emigrados cubanos Sociedad de Artesanos de Key West, en la que afirma conocer las ideas confederacionistas incluidas en el proyecto revolucionario de dicha asociación, y le informa su coincidencia con las de la Liga de las Antillas, de la que Betances es promotor y dirigente -conjuntamente con el general dominicano Gregorio Luperón- desde su fundación en París a fines de 1873 o principios de 1874 . Al presidente de aquella organización independentista cubana, Betances le expresa -con argumentos claramente anticipadores del antimperialismo que sería inherente a toda la actividad independentista y fusionista antillana- que el confederacionismo de "la Liga tiene por objeto mantener a nuestros países (Cuba-Puerto Rico-Santo Domingo-Haití) fuera del alcance de toda dominación extranjera (10).

1876: El periódico revolucionario cubano La voz de la Patria, editado en Nueva York y dirigido por J. Govantes (11), publica en octubre un editorial de contenido programático en el que hace una detallada exposición de sus principios; y especialmente destaca "Principio de unidad, paz y nacionalidad en las Antillas. Y principio de expansión hacia el Continente latino-americano". Entre los que expresan como Nuestros Fines, señalan los siguientes: "El establecimiento de la República y de la Democracia representativa en Cuba y Puerto Rico. La creación de una potencia ó personalidad internacional por medio de la Confederación de las Antillas. Y' la sustitución de la confraternidad sentimental que hoy aproxima tibiamente a las sociedades latino-americanas del Continente y de las Aritillas, con la fraternidad de intereses materiales, intelectuales y morales que ha de unirlas". A continuación, incluyen Dos Explicaciones fundamentales: "Conseguida

(8) Carta: de Francisco Vicente Aguilera a Gernán Cassé, Nueva York, 16 de mayo de 1873, Archivo Nacional, Fondo Donativos y remisiones, caja $660, n^{\circ} 1$. Agradecemos este documento al investigador Emilio Godínez Sosa.

(9) José de la Luz León: La diplomacia en la manigua, La Habana, ed. Lex, 1947, p. 74 (n).

(10) Ramón Emeterio Betances: "Carta interesante" en El Republicano, Cayo Hueso, 31 de octubre de'1874, año VI, no VIII, p. 1. Subrayado en el original.

(11) La Voz de la Patria, Nueva York, 6 de octubre de 1876, año I, n² 31, p. 2. 
nuestra independencia, o antes de consumada si es posible, trabajaremos por la de Puerto Rico (...)" Y añaden que "pretendemos la Confederación de las Antillas, para buscar elementos materiales y morales con que robustecer reciprocamente nuestro poder político, facilitar nuestro engrandecimiento en todos sentidos, y hacernos respetables y fuertes". Pocos días después (12), la publicación da a conocer una carta firmada por varias decenas de emigrados revolucionarios en la que participan a La Voz de la Patria "que dichos principios son los mismos que profesamos, y que creemos indispensables seguir, para alcanzar los altos fines que nos propusimos al combatir la dominación española". Entre los múltiples firmantes de esta carta ( $\mathrm{y}$ de las que en días sucesivos irá dando a conocer la publicación, provenientes de diferentes localidades de Estados Unidos) se encuentran personalidades revolucionarias de la importancia de Francisco Vicente Aguilera, Manuel de Quesada, Eugenio María de Hostos, Pío Rosado, y otros que aún habrán de desempeñar un papel de alta relevancia en la preparación y viabilización de la nueva guerra revolucionaria que poco más de tres lustros depsués habrá de organizar y dirigir -hasta su caída en combate- José Martí (13).

1876: En el propio mes de octubre, La Voz de la Patria publica, en números sucesivos, el programa del club revolucionario de emigrados cubanos y puertorriqueños Los Independientes (14), contentivo de bases similares a las reseñadas en los párrafos anteriores, y que destacan los objetivos confederacionistas que mueven su actividad independentista. Este club revolucionario habría de desempeñar un destacado papel en la organización -y en la radicalización- del nuevo proceso revolucionario que se iniciaría en 1895 .

1878: Menos de dos años después de estas evidencias documentales, aparecen los más tempranos testimonios conocidos de que -por un camino directamente vinculado a la práctica de la lucha independentista- uno de los principales jefes revolucionarios del siglo XIX cubano, el general Antonio Maceo, llegaba a la idea de unión antillana. Ello tiene lugar en febrero de aquel año, cuando algunos sectores participantes en la Guerra de los Diez Años dejaban languidecer (por causas que no es del caso analizar aquí) la lucha iniciada en 1868, y se firmaba el claudicante Pacto del Zanjón. Una parte del Departamento Oriental, encabezada precisamente por Maceo, estaría en contra del convenio de paz con España y protagonizaría la llamada Protesta de Baraguá, que José Martí habría más tarde de caracterizar como "de lo más glorioso de nuestra historia". Maceo se dirige entonces, a través de una proclama, a los habitantes del mencionado Departamento oriental, y afirma: "Nosotros tenemos diez años de penalidades y de fatigas sin cuenta; nuestro Ejército está fuerte, floreciente y aguerrido; con nuestra política de dar libertad a la esclavitud (...) debemos formar una nueva república asimilada con nuestra hermana la de Santo Domingo y Haiti" (15). No queda claro de la proclama maceísta si la propuesta se refiere a una asimilación relacionada sola-

(12) Ibid., 13 de octubre de 1876, año I, no 32, p. 2. Continuó en las siguientes entregas.

(13) Se trata fundamentalmente, entre otros, de José Francisco Madriz, Rafael de Castro Palomino y Manuel de la C. Beraza.

(14) La Voz de la Patria, Nueva York, entrega citada en nota 12 y entregas sucesivas.

(15) Antonio Maceo: "A los habitantes del Departamento Oriental" en Ideología política, La Habana, 1950, t. I, p. 101-2. En esta y en las demás notas, salvo indicación de lo contrario, los subrayados son del autor de este trabajo. 
mente con la región oriental de Cuba, o si se trata de una aspiración que supone la incorporación de todo el territorio cubano a las vecinas repúblicas. La historiografía cubana no ha abordado, hasta ahora, la cuestión, y no hemos hallado otras referencias al asunto en relación con este aspecto concreto. Pero es oportuno señalar muy particularmente que, por otra parte, este planteamiento ha contado con el apoyo de los demás jefes revolucionarios de aquella región (16).

1880: Apenas 17 meses después de la Protesta de Baraguá, ya a mediados de 1879 , se había iniciado en Cuba un nuevo y breve período de lucha que pasaría a nuestra historia con el singular nombre de Guerra Chiquita. Radicado temporalmente en Jamaica, y moviéndose por todo el ámbito antillano, Antonio Maceo realiza numerosas gestiones con el gobierno haitiano del general José Lamóthe y con el general dominicano Gregorio Luperón, a fin de lograr salir hacia Cuba en una expedición. Diversas causas le impiden llegar a territorio cubano e incorporarse al nuevo movimiento. Pero será precisamente durante los últimos meses de 1880 que nos encontraremos con una nueva y esclarecedora manifestación de las ideas confederacionistas del dirigente revolucionario, y de muy activos núcleos de los hombres que en Cuba mantienen en alto la lucha por la independencia. En efecto, ya casi a los finales de año -y sin que sea sino excepcionalmente mencionada por la historiografia cubana prerrevolucionaria- fue descubierta por el gobierno provincial colonial de Santiago de Cuba una conspiración que cubría una extensa zona del Departamento Oriental, y que se denominaba Liga Antillana. Se acusaba a la Liga Antillana, entre otras cosas, de que a su frente figuraba, conjuntamente con Antonio Maceo, el expresidente de la República Dominicana, Gregorio Iuperón, "con el propósito de fundar...la federación de Cuba, Puerto Rico y Santo Domingo" (17). Sólo en la historiografía española sobre Cuba puede hallarse alguna información -aunque muy parcial y parcializada- acerca de las características y objetivos de la conspiración, y siguiendo su invariable política de acusar de "guerra de razas" a todo intento independentista cubano, se afirma que "el programa de la Liga negra Antillana es... el predominio de la raza de color en las Antillas" (18). Entre los documentos conocidos, se encuentra la carta enviada desde Jamaica por un informante español que asegura que el movimiento conspirativo tiene ramificaciones en todas las Antillas, y "su centro está en Santo Domingo, Puerto Plata. Debe haberlo también en Haití. Aquí (en Jamaica) es pensamiento de Maceo y ha tomado forma y cuerpo con la Liga (...)(19). En medio de una fuerte represión que duró más de siete semanas y que produjo (único dato que recoge la historiografia prerrevolucionaria) más de 300 deportados de la entonces llamada "raza de color", los blancos encartados en esta Liga Antillana de objetivos republicanos confederacionistas fueron dejados en libertad, con el

(16) Entre ellos se hallaban jefes revolucionarios tan importantes como Flor Crombet, Vicente García, Guillermo Moncada y Pedro Martínez Freire.

(17) Gerardo Castellanos G.: Panorama bistórico, ensayo de cronología cubana; La Habana, García y Cía., 1934, vol. 2, p. 880.

(18) Antonio Pirala: Anales de la Guerra de Cuba, Madrid, 1898, t. III, p. 877. Ver también su Historia Contemporánea, Segunda parte de la Guerra Civil, Madrid, 1895, t. VI, p. 388-9, y Francisco J. Moya: Consideraciones militares sobre la campaña de Cuba, Madrid, imprenta del Cuerpo de Artillería, 1901, p. 232

(19) Ibid., p. 876 (n. 1). 
fin expreso -y reconocido por los historiadores españoles- de fomentar divisiones entre los cubanos blancos y los cubanos negros (20). Consideramos altamente expresiva de las ideas antillanistas tanto de Antonio Maceo como de amplios sectores de la población cubana en el período, la existencia de este movimiento que fue detectado, reprimido y desactivado sólo dos años y medio después de que el propio dirigente revolucionario propugnara -como hemos visto- la incorporación de Cuba (o de su región oriental) a las repúblicas de Santo Domingo y Haití (21).

1886: Es aproximadamente de este año que data un interesante y peculiar escrito del procer dóminico-cubano Máximo Gómez, titulado El Porvenir de las Antillas, y que si bien no fue publicado sino hasta muchos años después (22), recoge las ideas que sobre el conjunto de nuestras islas tenía -en los momentos en que acometía la organización de una nueva guerra de liberación en Cubaeste principalísimo jefe revolucionario. Al escribirlo, el general independentista se sitúa hipotéticamente a mediados del siglo XX, y narra detalladamente-como pasado ya histórico- lo que entonces aspira a que fuera el porvenir de las islas antillanas: una gran revolución que las involucre a todas, junto con una parte de la cuenca del Caribe. Según su previsión, esta revolución daría por resultado la sustitución de las clases altas -hasta entonces en el poder- por las clases populares, integradas mayoritariamente por negros y mestizos, que contarían con el apoyo de una amplia parte de la población blanca (23). En Cuba y Puerto Rico, aún ante los fracasos revolucionarios de Yara y de Lares, "la clase baja y los esclavos recogían poco a poco la herencia que les legaban esas muertas revoluciones". Las demás Antillas veían el desarrollo de los acontecimientos en ambas islas, y en ellas, "en su mayoría del mismo origen y con una misma historia, con las mismas cicatrices, por iguales heridas, fácil era (...) la unificación de la idea que produjera una Revolución de vastísimos horizontes y que debía conmoverlo todo". El propósito se extendió entre los pueblos antillanos facilitado por "la amistad, por la proximidad, y la identidad, con Santo Domingo, Haití, Jamaica,

(20) Antonio Pirala: Anales..., t. III, p. 876. La fuente cubana que menciona las detenciones resultantes de la represión colonialista consiguiente, es: Emilio Bacardí: Crónicas de Santiago de Cuba, 1923, t. VI, 367-8 (n. 345).

(21) Sin lugar a dudas, en el largo proceso de la actividad revolucionaria de Antonio Maceo, el logro de la independencia de Cuba no sería, en modo alguno, el límite de su acción. Clara expresión de ello es su afirmación, ya en esos mismos años (1884); reiterada después en más de una ocasión: "Cuando Cuba sea independiente, solicitaré del gobienno que se constituya, permiso para hacer la libertad de Puerto Rico, pues no me gustaría entregar la espada dejando esclava esa porción de América". (Ver: Antonio Maceo: "A Anselmo Valdés", op. cit., p. 246 ).

(22) Este documento -inédito hasta 1946- fue encontrado por Andrés Vargas Gómez, quien considera que data del año 1886, aproximadamente. Fue reproducido bajo su mismo título original de "El Porvenir de las Antillas" por la revista Carteles, de La Habana, en los números 46 y 47 , de 15 y 22 dfe noviembre de 1942, respectivamente, de donde tomamos las citas incluidas en el presente trabajo. Debemos la noticia acerca del mismo al investigador César García del Pino.

(23) Identifica Gómez - y al hacerio responde, aunque sea parcialmente, a una realidad social de su tiempo- el problema racial con el problema social: identifica las clases populares más preteridas y humildes con los grupos étnicos de negros y mestizos, y a la raza blanca con lo que él llama "las clases elevadas". 
La Trinidad, las Guayanas inglesas y todo el archipiélago de las Bahamas". Y muy pronto la raza de color (incluidos los negros del sur de Estados Unidos) "entrevió en las Antillas no solamente un refugio para vivir como hombres, sino una futura patria para sus hijos". En poco tiempo-dice- cundió "por toda la América antillana la idea de la "revolución de los desheredados". Y ello representó la celebración de "la perpetua alianza entre las Antillas, reanudando los lazos de antiguo rotos por la conquista". Aunque no llega a aclarar en su relato cuál fue la forma política que adoptó esa alianza, sí precisa que, antes de la que ha llamado la revolución de los desberedados, "las Antillas hermanas entre si no tenían comunicación, y se vivía en el aislamiento en medio del mar Caribe". Ahora, una vez realizada esa revolución, "la historia nos está probando (...) que del pasado atraso en que por tantos años vivieron estacionadas estas Ántillas, su principal causa consistía en el lastimoso y contranatural aislamiento que entre todas ellas existía" (24). Pero hacia la última década del XIX ya no parece tener esperanzas de una unión formal de nuestras repúblicas, y previendo - en nuevas circunstancias continentales- nuevas formas de unidad de las naciones antillanas, reclama: "Sueño con una ley que con muy insignificantes restricciones declarase (y lo mismo con Puerto Rico cuando fuese libre) que el dominicano fuese cubano en Cuba, y viceversa" (25).

Aún en la frontera misma del siglo -cuando la realidad de la dominación española ya había sido superada por el nuevo ( $y$ aún mayor) peligro de la dominación del naciente imperialismo estadounidense- el ya entonces anciano héroe revolucionarió escribe al támbién prócer antillano Eugenio María de Hostos ofreciéndole: su esfuerzo y su espada para contribuir a conjurar "la angustiosa situación de Puerto Rico que, por artes diplomáticas, pasará de colonia española a tierrá conquistada por los américanos" (26). Días después, ratifica públicamente' su ofrecimiento, y añade: "es, y debe ser, para nosotros antillanos, un gran dolor ver que mueren las esperanzas de hacer de (Puerto Rico), que es una de las très Grandes Antillas, la República que unida a la cubana y la dominicana fuese legítimo timbre de orgullo para nuestras razas, realizándose así, y por modo completo, la aspiración constante de todos los corazones honrados y levantados (27). En las circunstancias concretas que la realidad histórica imponía, y lejos ya de concebir la creación inmediata de una nación antillana unificada, no abandonaba, sin embargo, su concepción de las Antillas como un todo único llamado a un porvenir relevante, por cuyo devenir colectivo seguía dispuesto a luchar.

(24) Hacia 1887, precisamente en los mismos años en que calcula escribía el trabajo que reseñamos, acudía Máximo Gómez a Ramón Emeterio Betances en busca de apoyo para propiciar un movimiento revolucionario conjunto de Cuba y Puerto Rico, (Ver: Emilio Godinez y Haroldo Dilla: "Prólogo", en su Ramón Emeterio Betances, La Habana, Casa de las Américas, Col. Pensamiento de Nuestra América, 1983, p. 41).

(25.) Máximo Gómez: "Odisea del general José Maceo" en su Revoluciones... Cuba y hogar; Comp. de Bernardo Gómez Toro, La Habana, 1927, pp. 95-6.

(26.) Máximo Gómez: "Carta a Eugenio María de Hostos"; en Ramón de Armas: La revolución pospuiesta, La Habana, Ed. de Ciencias Sociales, 1975, p. 173.

(27) Cit. por Emilio Roig de Leuchsenring en su "Hostos, apóstol de la independencia y de la libertad de Cuba y Puerto Rico", Hostos y Cuba, Ed. de Ciencias Sociales, Instituto Cubano del Libro, p. 107. 
1887-1895: Mucho se acercaba la comprensión del prócer dominico-cubano a la que José Martí -verdadero político revolucionario del siglo XX-había desarrollado en relación con las posibilidades de acercamiento y unión de las Antillas, en momentos históricos en que ya detectaba que -más que en el aún existente empuje anexionista de Estados Unidos sobre sus territorios más cercanos- el expansionismo norteamericano se basaba ahora en nuevos métodos indirectos de penetración y dominios económicos que acrecentaban el peligro para el conjunto de las repúblicas latinoamericanas y, de manera más inmediata, para nuestras tierras antillanas: era precisamente en estas últimas donde Estados Unidos intentaba entonces convertirse -a través del mecanismo de convenios y tratados (28)- en "los señores pacíficos y proveedores forzosos de todas las Antillas", y donde su creciente poderío amenazaba con "lograr restablecer con otros métodos y nombres el sistema imperial" (29). Ahora, ya no se trataría solamente de "aprovechar la libertad en beneficio de los humildes, que son los que han sabido defenderla" (30), ni de morir -en Cuba o en Puerto Rico- en defensa de "la libertad verdadera: no por la libertad que sirve de pretexto para mantener unos hombres en el goce excesivo, y a otros en el dolor innecesario" (31). Ahora, la independencia de ambas islas sería, además, imprescindible para arrebatarle al naciente imperialismo sus presas más probables, y quitarle - con ello- las posibilidades de fortalecerse y ganar sustento adicional para lanzarse sobre las demás tierras de América (32).

En Martí, en efecto, su comprensión de la coyuntura americana en los momentos en que se inicia la época histórica del imperialismo, le ha permitido elaborar una estrategia revolucionaria continental capaz de enfrentar el nuevo fenómeno histórico que amenaza a la parte nuestra del continente (y que presupone, además, profundas transformaciones en cuyo análisis no tenemos aquí oportunidad de detenernos). De esa estrategia es premisa insoslayable el inicio de la guerra de liberación nacional que debe garantizar la independencia de Cuba y Puerto Rico, y hacer posible el cumplimiento de "los deberes mayores que la geografia, la vecindad temible y el problema del continente y de la época" (33) imponen a ambas islas. Y el papel que la coyuntura continental les asigna se define en la alternativa de ser "mero pontón de la guerra de una república imperial -mero fortín de la Roma americana-", o ser, en el continente, "la garantía del equilibrio, (y) la de la independencia para la América española, aún amenazada" (34).

(28) José Martí: "Correspondencia a La Nación, de Buenos Aires", en sus Obras completas, La Habana, Ed. de Ciencias Sociales, 1975, t. VIII, p. 88 (1885).

(29) José Martí: "La Conferencia Monetaria de las Repúblicas de América" en Ibid., t. VI, p. 165 (1891).

(30) José Martí: "Carta a José Dolores Poyo", en Ibid., t. I, p. 212 (1887).

(31) José Martí: "Vengo a darte patria: Puerto Rico y Cuba", en Ibid., t. II, p. 255 (1893).

(32) Ya, a estas alturas del siglo, estaba para Martí clara la necesidad de cerrar a Estados Unidos la oportunidad de absorber -por métodos directos o indirectos- "las dos tierras de Cuba y Puerto Rico que son, precisamente, indispensables para la seguridad, independencia y carácter definitivo de la familia hispanoamericana en el continente, donde los vecinos de habla inglesa codician la clave de las Antillas para cerrar con ellas todo el Norte por el istmo, y apretar luego con todo ese peso por el Sur. Si quiere libertad nuestra América, ayude a hacer libres a Cuba y Puerto Rico". (José Martí: "Otro Cuerpo de Consejo", en Ibid., p. 373 (1893).

(33) José Martí: op. cit., n. 31, p. 257.

(34) José Martí: "El tercer año del Partido Revolucionario Cubano. El alma de la Revolución y el deber de Cuba en América", en op. cit., t. IIIm p. 142 (1894). 
El alcance transformador y antiimperialista -de verdadera liberación nacional contemporánea- que para Martí tenía la nueva etapa de lucha ya a punto de iniciarse en Cuba, lejos de excluir; presuponía la consolidación de la independencia de las Antillas ya republicanas: una independencia nacional no vulnerable por los nuevos métodos de absorción de aquella "república imperial"; de una plena liberación nacional que incluyera a las Antillas que ya ostentaban la condición republicana, y que hiciera posible, finalmente, "la creación de una rchipiélago libre (...)" (35).

Pero ya en las nuevas circunstancias continentales, la unión antillana no podrá ser concebida como una posible confederación o unión formal de otro tipo. Para Martí, la unión antillana dependería entonces -eso sí- dela acción unida de los pueblos de nuestros territorios; de la acción coordinada de nuestras naciones insulares. Sabe que las Antillas constituyen una unidad, y que en ellas "crecen, con el orden intuitivo y oprtuno de la naturaleza, las fuerzas creadoras que (...) compondrán, bajo la guarda del mar y de la historia, la nación futura" (36). Pero deja ver con claridad las cortas posibilidades que de inmediato atribuye a esa futura nación, y precisa: "No parece que la seguridad de las Antillas, ojeadas de cerca por la codicia pujante, depende tanto de la alianza ostentosa y, en lo material, insuficiente, que provocase reparos y justificara la agresión, como de la unión sutil, y manifiesta en todo, sin el asidero de la provocación confesa, de las islas que han de sostenerse juntas, o juntas han de desaparecer, en el recuento de los pueblos libres" (37).

La realidad continental de la última década del siglo XIX, a los ojos de Martí, ya no lo permite, sin la premisa de una América Latina que haya logrado, también, su "segunda independencia" (38). Trabaja por alcanzar el momento en que una nueva situación de la totalidad de nuestras tierras lo hará factible, y por ello, cuando ya iniciada la década del 90 se encuentre en Haití con Anthenor Firmin, el importante líder de aquel país podrá testimoniar que Martí apoya y comparte la aspiración de crear una Confederación Antillana. Pero ya se trata, sin embargo, de un objetivo a lograr en el futuro: entonces, todavía, "por la rivalidad de los productos ágrícolas, o por la diversidad de hábitos y antecedentes, o por el temor de acarrearse la enemiga del vecino bostil, pudieran venir a apartarse, en cuanto cayese en forma cerrada su unión natural, las tres islas que, en lo esencial de su independencia y en la aspiración del porvenir, se tienden los brazos por sobre los mares, y se estrechan ante el mundo, como tres tajos de un mismo corazón sangriento, como tres guardianes de la América cordial y verdadera, que sobrepujará al fin a la América ambiciosa, como tres hermanas" (39).

Lo reseñado, desde luego, no agota la presencia de las ideas confederacionistas en los proyectos revolucionarios nacidos del pueblo cubano y sus más importantes y legítimos representantes, y que tan poco espacio han hallado en nuestra historiografía. Permite, sin embargo, contribuir a ratificar que, en el con-

(35) José Marti: "Manifiesto de Montecristi. El Partido Revolucionario Cubano a Cuba", en op. cit., t. IV, p. 101 (1895).

(36) José Martí: "Las Antillas y Baldorioty Castro", en Ibid., p. 405 (1892).

(37) Ibid

(38) José Martí: "Congreso Internacional de Washington. Su historia, sus elementos y sus tendencias. I", en Ibid., t. VI, p. 46 (1889).

(39) José Martí, loc. cit., n. 36. 
junto de los luchadores independentistas cubanos de los años 60,70 y 80 , tuvieron ininterrumpida fuerza y vigencia esas ideas que, conjuntamente con otras de similar importancia, caracterizaron a la que hoy -siguiendo la acertada tesis del recientemente desaparecido historiador y antillanista cubano Emilio Godínez Sosa- puede ser caracterizada como vanguardia revolucionaria antillana de la segunda mitad del siglo XIX (40).

Pero precisamente los propios rasgos apuntados como comunes a estos hombres que sustentaron con fuerza las ideas confederacionistas en cuba y en las demás Antillas, parecen haber constituido uno de los factores de mayor peso para que la historiografía cubana prerrevolucionaria no haya abordado su estudio, ni haya reconocido estas ideas como elementos de suma importancia dentro de muy significativos sectores del independentismo cubano. En efecto, la idea de Confederación Antillana ha estado permanentemente vinculada, aunque con diferentes grados de intensidad y explicitación:

(40) Esta vanguardia está constituida por un grupo de destacados revolucionarios antillanos del periodo en cuestión: Betances, Hostos, Luperón, Gómez, Maceo, Meriño, algunos dirigentes haitianos que aún hoy permanencen casi totalmente desconocidos, y -desde luego- la figura a quien su tiempo histórico y las circunstancias continentales en las que penetró contribuyeron a colocar en la posición más avanzada de la misma: José Martí.

Todos ellos, y otros que pudieran también ser mencionados, actían con una muy definida conciencia de antillania, que se expresa, en primer término, en el reconocimiento de las Antillas como un conjunto dotado no sólo de unidad geográfica, sino de unidad histórica y -sobre todo-nacional; y que llevaba a la conformación de lo que algunos de estos hombres llamaron, indistintamente, "raza antillana" o "nacionalidad antillana".

Se expresa además en el reconocimiento de la necesidad de integración de los diferentes países en que se asienta dicha nacionalidad, no sólo para garantizar su perentorio progreso individual y colectivo, sino también para defender al conjunto de las islas de la siempre presente amenaza de absorción colonialista por potencias europeas, y de la voracidad expansionista que, bajo distintas formas, toda esta vanguardia - con mayor o menor grado de intelección y de acierto- ya percibía como nuevo peligro, procedente esta vez del poderoso vecino común del Norte del continente. Esta conciencia de antillanía no implicaba, sin embargo, que se viera a las islas antillanas como diferenciadas o desvinculadas del resto del mundo latinoamericano: muy por el contrario (y este es un tercer elemento, de gran importancia), la independencia y la unidad de los territorios insulares debía contribuir a garantizar la total independencia de las demás repúblicas latinoamericanas, y hacer posible el imprescindible y urgente equilibrio entre los dos componentes desiguales del continente. Otro de los rasgos comunes a estos hombres se vinculaba $-\mathrm{y}$ este cuarto elemento es de trascedencia singular- a su filiación o compromiso junto a los sectores más humildes y desposeídos de la población de nuestros países, sin que esto significara en modo alguno un rompimiento clasista -entonces imposible e innecesario- con los elementos que el período en cuestión tenían el privilegio de la cultura, o incluso el dominio de los medios fundamentales de producción, incluida la tierra. Lo que sí resultó siempre claro fue su profundo democratismo, que se expresaba en su abierto compromiso de redimir y abrir espacio social y político a los grupos sociales de más humilde extracción, a los cuales consideraban principalísimos beneficiarios -si bien no ünicos- de las transformaciones que propugnaban. Debe quedar entendido, sin embargo, que en una buena parte de los casos, el estudio profundo y completo del pensamiento social de estos hombres está aún. por realizar, y que es ello lo que permitirá precisiones y conclusiones definitivas en relación con este último aspecto mencionado. 
Primero, al reconocimiento del determinante peso que en nuestras sociedades insulares tenía (y tiene) la población negra y mestiza, de originaria procedencia africana, y de que su mixturación con la población blanca de origen español $\rightarrow$ o de otras procedencias- y con los elementos supervivientes de la población autóctona de nuestras islas ha conducido a la existencia de una "raza" o "nacionalidad" antillana que era -yi en muchos lugares aún es- menester reivindicar, y que (como hemos visto) constituía para muchos precisamente la base de la unificación formal a la que para nuestras islas aspiraban. Esete factor, desde luego, habría de constituir un elemento inhibitorio para el abordaje del tema por la historiografía prerrevolucionaria, en un país en el que -como Cuba- la esclavitud había perdurado hasta dos décadas antes de su proclamación republicana, el mestizaje no había - por ello- tenido el mismo intenso desarrollo que en otros territorios antillanos, y sus clases cultas habían sido educadas -como en más de una oportunidad señalara José Martí- para la discriminación y la exclusión del negro y del mestizo.

Segundo, y estrechamente vinculado al punto anterior, la idea de Confederación Antillana fue invariablemente propugnada, tanto en Cuba como en las demás Antillas, por hombres que aspiraban a abrir un urgente espacio político y social a los sectores más desposeídos y desheredadós de nuestra soceidad, que fueron los grandes derrotados en el desenlace desfavorable de la Revolución martiana de:1895, y que eran en gran medida coincidentes con los mencionados estamentos sociales rechazados y excluidos a causa de su origen étnico. Por otra parte, las ideas confederacionistas nunca fueron sostenidas en Cuba -hasta donde tenemos conocimiento- por los ideólogos y activistas políticos de las clases en cuyas manos estaban los medios fundamentales de producción, e interesados -por el contrario- en fortalecer y consolidar su dominio económico en el seno de nuestra sociedad.

Tercero, las ideas confederacionistas tuvieron invariablemente un sentido defensivo (como ya se ha señalado) en relación con toda dependencia de potencias extranjeras, incluida la nueva potencia imperialista entonces en desarrollo en la parte norte del continente. Habiendo sido ésta - con sus aliados internos- la que resultara triunfante en la guerra anticolonial que en Cuba tuvo, además, un verdadero contenido de liberación nacional contemporánea, no es de extrañar que la historiografía de las dependientes clases dominantes cubanas no se mostrara interesada en abordar ni destacar proyectos que, por su propia esencia, estaban en contra de sus propios intereses clasistas. No puede pasarse por alto el hecho de que a partir de la llamada Guerra de Independencia, en Cuba quedaba entronizada la dependencia neocolonial con respecto a Estados Unidos, a la vez que para Puerto Rico -elemento determinante en el proyecto de Confederación Antillana- se mantuvo inalterada la condición colonial, esta vez bajo el dominio de la nueva potencia imperial.

Pero todo ello, siri embargo, no alcanzaría a explicar las causas por las que los muy importantes historiadores progresistas y revolucionarios que dejaron huella indeleble en nuestra historiografía de la primera mitad del presente siglo tampoco hayan dado espacio al estudio de los proyectos e ideas confederacionistas -a pesar del indudable clima político adverso-, como sí lo hicieron, con voluntad y éxito nada desatendibles, en relación con la aspiración nacional a una absoluta soberanía e independencia, con las ideas antiimperialistas, y -aunque en menor 
medida- con las concepciones latinoamericanistas e integracionistas, muy particularmente a través del estudio del pensamiento y la acción de José Martí. No parece desacertado considerar que una de las causas fundamentales de ello radique precisamente en que por la extraordinariamente influyente figura de Martí ya se hace un abordaje de la unión antillana correspondiente-como hemos visto- a la estrategia revolucionaria que para la totalidad del continente concibe, sustituyendo las aspiraciones confederacionistas o de unión formal por las entonces más factibles y reales de unión sutil entre los pueblos antillanos.

Solamente cuando la historiografía postrevolucionaria se propuso rescatar y sacar a la luz aspectos de la historia nacional relegados o desatendidos por una buena parte de la precedente (al influjo, desde luego, de la renovación imperante en el propio país, y de la nueva y urgente situación continental que durante la segunda mitad de nuestro siglo va tomando cuerpo), las ideas de integración latinoamericana irían ocupando el espacio que nunca debió de faltarles en las obras de nuestros historiadores, y comenzarían (pero sólo comenzarían) a ser estudiadas y atendidas las concepciones antillanistas de los pensadores y dirigentes revolucionarios cubanos y de otros países antillanos (41).

Ciertamente, falta mucho todavía por hacer, en momentos en que tanto las unas como las otras han cobrado nueva magnitud y nueva vigencia, en el contexto de la lucha actual de los pueblos de nuestra América por garantizar su definitiva y verdadera independencia, y su irrenunciable derecho al desarrollo. $Y$, de ese mismo modo, ha cobrado también nueva magnitud y nueva vigencia la firme convicción de José Martí de que

"La independencia de Cuba y Puerto Rico no es sólo el medio único de asegurar el bienestar decoroso del hombre libre, en el trabajo justo, a los habitantes de ambas islas, sino el suceso histórico indispensable para salvar la independencia amenazada de las Antillas libres, la independencia amenazada de la América libre, y la dignidad de la república norteamericana.

¡ Los flojos, respeten, los grandes, adelante! Esta es tarea de grandes" (42).

(41) En esta dirección se destacan los valiosos y precursores trabajos del prematuramente desaparecido compañero Emilio Godínez Sosa, quien rescató y antologizó un voluminoso material, hasta entonces desconocido, de Ramón Emeterio Betances y Eugenio María de Hostos. Otros historiadores cubanos, como Rodolfo Sarracino, Francisco Pèrez Guzmán, Josefina Toledo, René González Barrios, Angel Iglesias, Patricio Bosch y Salvador Morales han dado particular atención en sus obras historiográficas a las vinculaciones entre el proceso independentista cubano del siglo XIX -y sus protagonistas- y la solidaridad de y con las demás islas antillanas, y a las ideas de los integrantes de la mencionada vanguardia revolucionaria antillana. También el autor de esta comunicación ha realizado algunos esfuerzos en el mismo sentido.

(42) José María Martí: op. cit., n. 34. p. 143. 